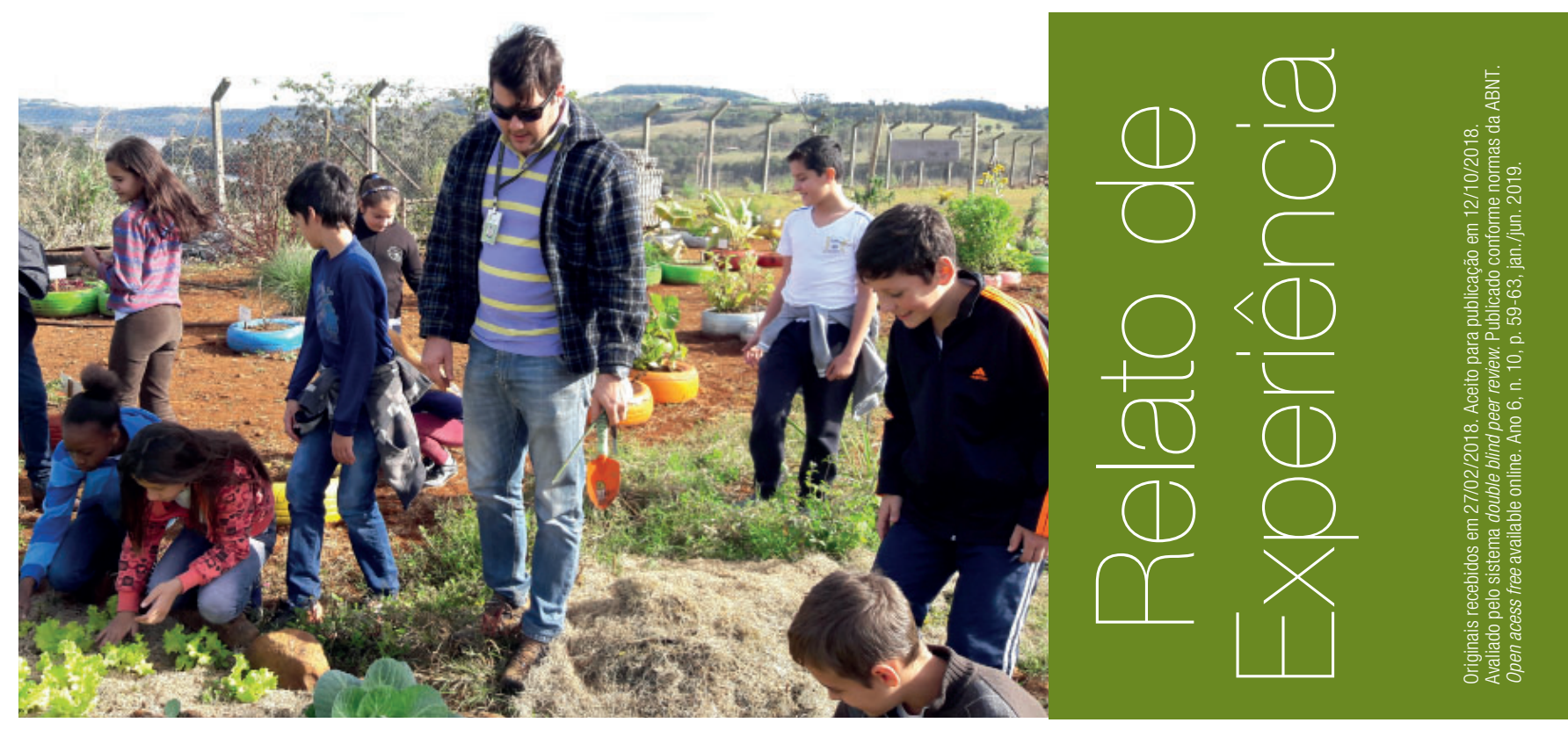

\title{
Primeira Semente: Oficinas de Educação Ambiental na Educação Básica
}

\author{
Djeniffer Nogueira - djeniffer.nogueira@hotmail.com ${ }^{1}$ \\ Graziele Baierle - grazi95baierle@hotmail.com ${ }^{2}$ \\ Mateus Potrich Bellé - mateus.belle@ifsc.edu.br ${ }^{3}$ \\ Daiana Schmidt - daiana.schmidt@ifsc.edu.br ${ }^{4}$
}

\section{RESUMO}

Foram realizadas oficinas de educação ambiental com os alunos do quarto e do quinto ano do ensino fundamental, da Escola de Educação Básica Irineu Bornhausen, situada em Águas de Chapecó, no estado de Santa Catarina. 0 objetivo deste trabalho foi promover a conscientização dos alunos da educação básica em relação às responsabilidades individuais e coletivas na preservação do equilíbrio ambiental. Como resultado, observou-se a conscientização desses alunos em relação à preservação do meio e despertou-se interesse acerca das plantas medicinais e modos de produção sustentável.

\section{PALAVRAS-CHAVE}

Educação ambiental. Sustentabilidade. Ética.

\footnotetext{
1 Bolsista do projeto. Discente do curso técnico em Aquicultura do Instituto Federal de Educação, Ciência e Tecnologia de Santa Catarina / Câmpus São Carlos.

2 Bolsista do projeto. Discente do curso técnico em Aquicultura do Instituto Federal de Educação, Ciência e Tecnologia de Santa Catarina / Câmpus São Carlos.

3 Coordenador adjunto do projeto. Engenheiro Agrônomo. Doutor em Engenharia Agrícola. Docente do Instituto Federal de Educação, Ciência e Tecnologia de Santa Catarina / Câmpus São Carlos.

4 Coordenador do projeto. Engenheira Agrônoma. Doutora em Ciências. Docente do Instituto Federal de Educação, Ciência e Tecnologia de Santa Catarina / Câmpus São Lourenço do Oeste.
} 


\section{ABSTRACT}

Environmental education workshops were held with elementary school students from Irineu Bornhausen Elementary School, located in Aguas de Chapecó in the state of Santa Catarina. The objective of this work was to promote awareness of individual and collective responsibilities in preserving the environmental balance from basic education students. As a result, the students' awareness of the preservation of the environment and an interest in medicinal plants and sustainable production methods were observed.

\section{KEYWORDS}

Environmental education. Sustainability. Ethic.

\section{Relato de experiência}

A educação ambiental, segundo a Lei no 9.795/99, é um componente essencial e permanente da educação nacional, devendo estar presente, de forma articulada, em todos os níveis e modalidades do processo educativo, em caráter formal e não-formal (Artigo $2^{\circ}$ ) e não deve ser implantada como disciplina específica (Artigo 10) (BRASIL, 1999).

As Diretrizes Curriculares Nacionais (DCNs) para a Educação Ambiental, parecer de n 14/2012 do conselho pleno do Conselho Nacional de Educação (CNE), situam a importância e estabelecem a obrigatoriedade do debate da Educação Ambiental na Educação Básica. Para orientar sua efetivação como conteúdo transversal, as DCNs propõem que seu planejamento curricular promova, dentre outras estratégias, a realização de projetos e atividades, inclusive artísticas e lúdicas. As atividades devem valorizar o sentido de pertencimento dos seres humanos em relação à natureza, à diversidade dos seres vivos, às diferentes culturas locais e à tradição oral. Além disso, as atividades podem ser desenvolvidas em espaços nos quais os estudantes se identifiquem como integrantes da natureza, estimulando a percepção do meio ambiente como fundamental para o exercício da cidadania (BRASIL, 2013).

Considera-se que as questões ambientais estão cada vez mais frequentes no cotidiano da sociedade contemporânea, sendo elas essenciais nos processos educativos, principalmente nos anos iniciais da escolarização. 0 mundo cada vez mais globalizado, com acelerado crescimento das cidades, que trocam os espaços verdes por cimento, diminui drasticamente o contato das crianças com o meio ambiente. Desta forma, entende-se que a educação ambiental nas escolas contribui para a formação de adultos conscientes e mais preparados para tomar decisões, de modo a se comprometerem com a vida e o bem-estar da sociedade (BARBOSA DE MEDEIROS et al., 2011).

A partir desse contexto, o objetivo geral deste projeto de extensão foi desenvolver atividades fundamentadas na educação ambiental para alunos do ensino fundamental da rede pública de ensino, a fim de proporcionar uma visão holística do meio ambiente e promover a conscientização quanto às responsabilidades individuais e coletivas na preservação do equilíbrio ambiental. Para tanto, foram realizadas seis oficinas de educação ambiental no período de 6 de maio a 6 de outubro de 2017 para alunos do $4^{\circ}$ e do $5^{\circ}$ ano do ensino fundamental da Escola de Educação Básica Irineu Bornhausen, no município de Águas de Chapecó, estado de Santa Catarina (SC), totalizando o envolvimento direto de 80 alunos. Cada oficina teve duração média de três horas e foi realizada nas dependências do IFSC Câmpus São Carlos (SC) e da referida escola. Todas as oficinas foram realizadas priorizando-se o protagonismo dos alunos extensionistas e participantes do projeto. Essa metodologia permitiu a construção do conhecimento pelos próprios alunos e promoveu o processo dialético de ação-reflexão-ação, processo este qualificado pela contribuição dos pares e do professor.

A primeira oficina realizada abordou o tema "Reciclagem", em que foram apresentados os princípios básicos da reciclagem, proporcionando a compreensão dos diferentes tipos de resíduos sólidos (plástico, metal, papel, vidro, orgânico e não reciclável), conforme Resolução 
Conama $n^{0} 275$ (CONAMA, 2001). Os alunos já conheciam as lixeiras para separação, no entanto ainda não compreendiam como fazer e qual a importância de realizar a separação de cada material. A prática de separação agregou valor à oficina, pois os alunos puderam separar os materiais e colocar em prática o conhecimento debatido pelo grupo (Figura 1).

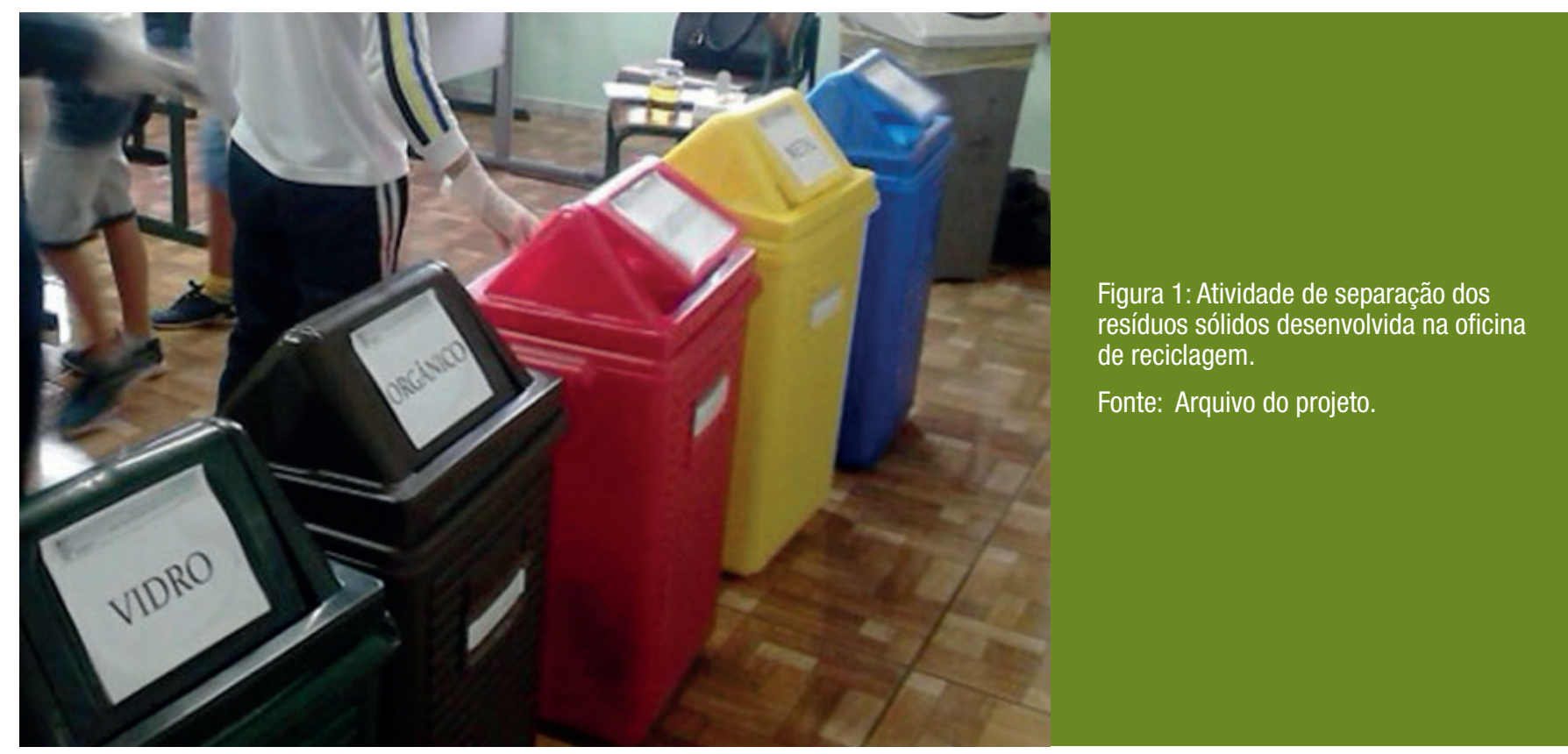

Na segunda oficina foram apresentados os conceitos e princípios do processo de "Compostagem" e a montagem de uma composteira doméstica. A participação efetiva dos alunos nessa oficina (Figura 2) buscou integrar o conhecimento teórico e a prática, proporcionando o desenvolvimento de habilidades para a formação de um indivíduo consciente de seus atos por meio da reciclagem dos resíduos sólidos, reutilizando produtos e reduzindo a produção de lixo descartado no ambiente.

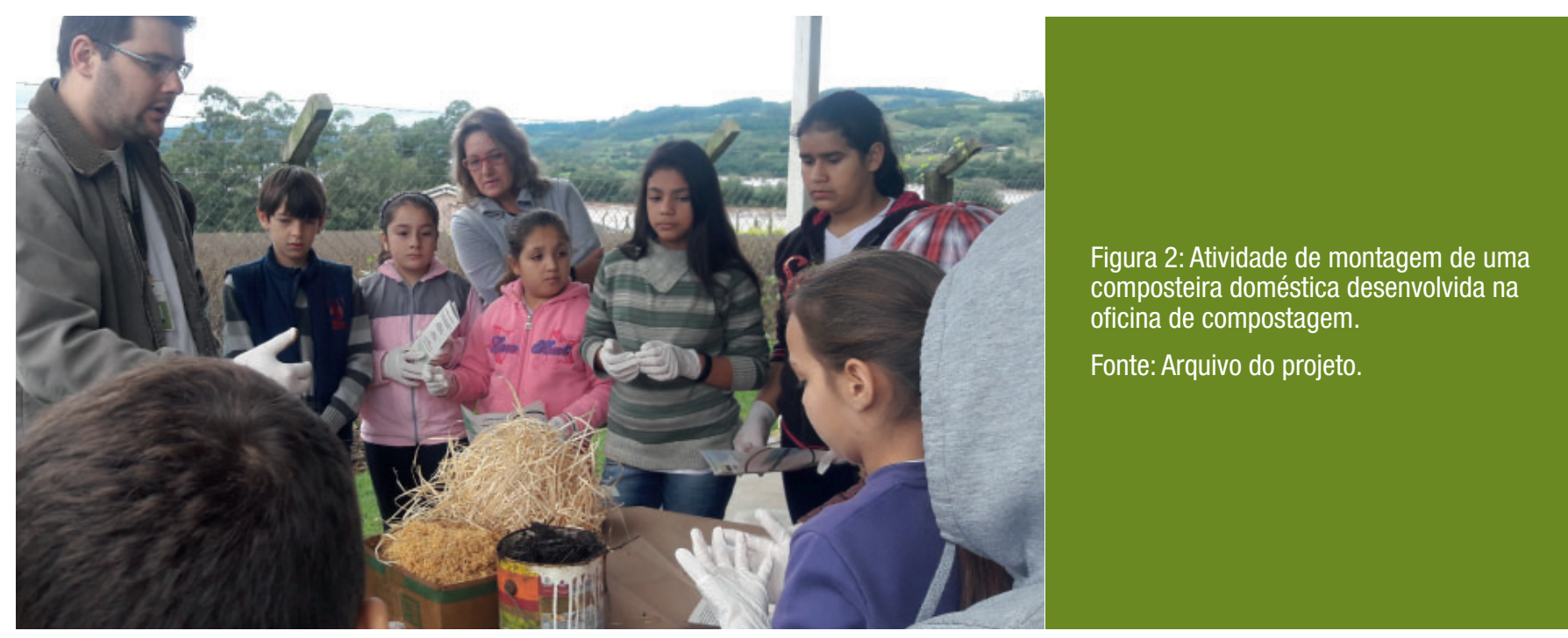

Na terceira oficina abordou-se o tema "Como as plantas funcionam". Os conceitos de ser vivo, fases do desenvolvimento da planta, processo de germinação e fotossíntese foram trabalhados por meio da construção do boneco ecológico em duas condições diferenciadas de luminosidade (Figura 3). 
Figura 3: "Boneco Ecológico" desenvolvido na oficina Como as Plantas Funcionam.

Fonte: Arquivo do projeto.

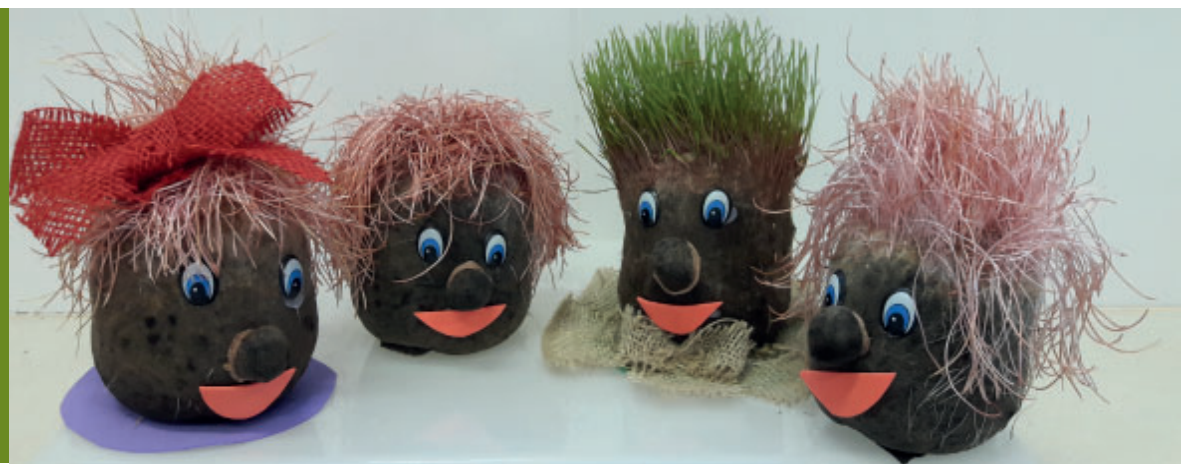

Essa atividade objetivou demonstrar, com uma alternativa rápida e de forma concreta, o desenvolvimento da planta a partir da semente e todas as condições necessárias ao seu crescimento e desenvolvimento normais. Os alunos foram capazes de compreender a importância da água no processo de germinação e a importância da luz no processo da fotossíntese (Figura 4).

Figura 4: Resultado da atividade de construção do "Boneco Ecológico" desenvolvido na oficina Como as Plantas Funcionam.

Fonte: Arquivo do projeto.

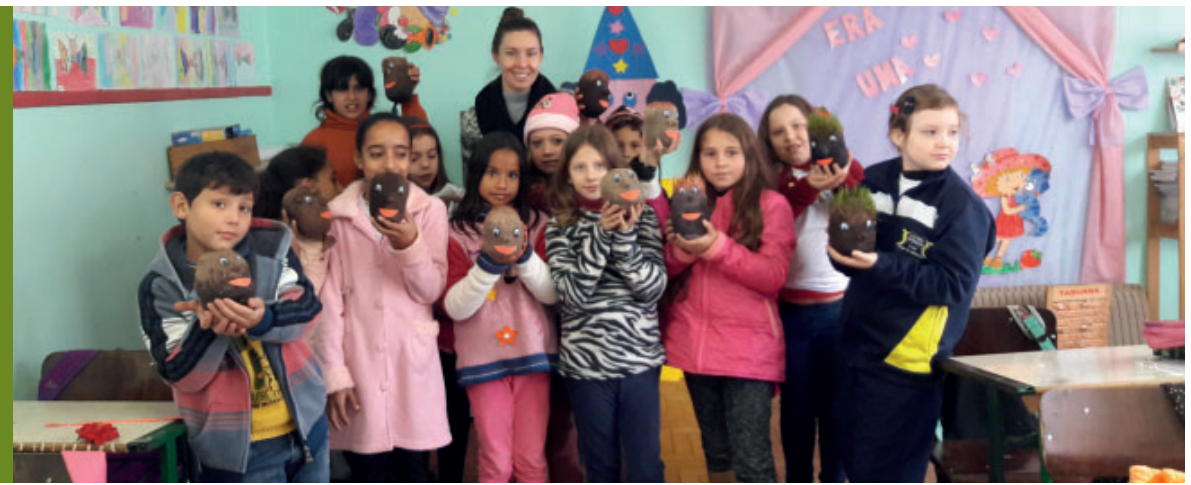

A oficina Identificação de Espécies de Plantas Medicinais foi realizada no horto medicinal do IFSC Câmpus São Carlos, que conta com uma coleção de 60 espécies. A visita (Figura 5) foi dividida em dois momentos: visita livre e visita guiada. No momento livre, os alunos puderam trocar experiências com os colegas e esclarecer dúvidas sobre as plantas que mais os interessaram. No segundo momento, foram selecionadas dez plantas de uso mais comum na região, apresentadas as suas principais características morfológicas para diferenciação de espécies não medicinais e as suas indicações e contraindicações. Os alunos expressaram a compreensão coletiva dessa oficina por meio da confecção de cartazes que foram expostos no IFSC e, posteriormente, na sua escola. Essa atividade valorizou o trabalho e o conhecimento de cada aluno, o que foi muito motivador para a continuidade das atividades do projeto.

Figura 5: Visita realizada ao horto medicinal do IFSC Câmpus São Carlos, referente às atividades da oficina Identificação de Espécies de Plantas Medicinais.

Fonte: Arquivo do projeto.

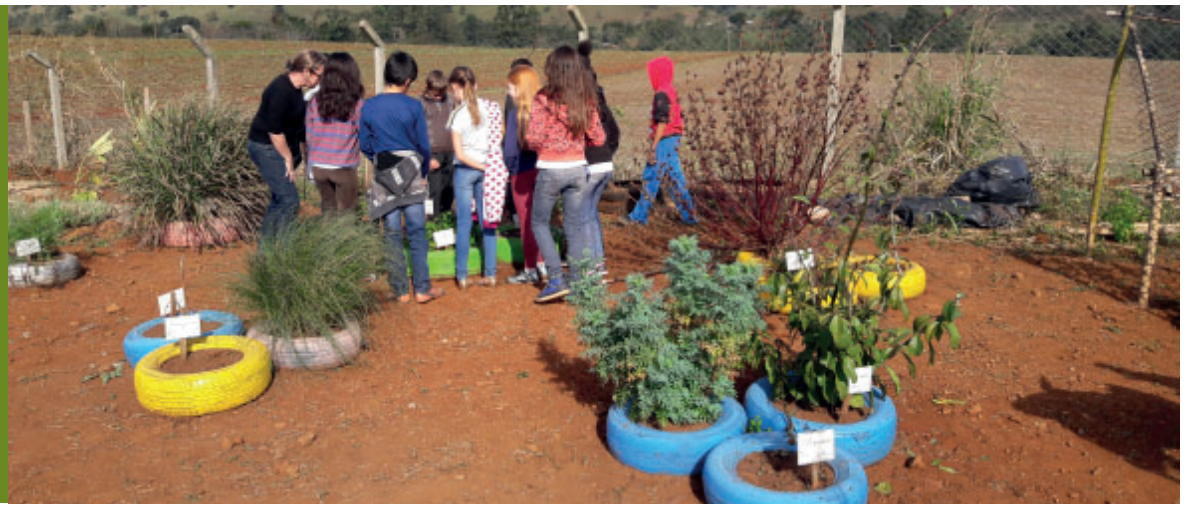

A quinta oficina abordou o tema produção de mudas e manejo agroecológico de plantas medicinais. Nessa oficina, priorizou-se a integralização de todos os temas trabalhados nas demais oficinas, com a inserção do conceito de reprodução vegetal e 0 conhecimento dos principais cuidados que devem ser tomados para o desenvolvimento de uma nova planta. Cada 
aluno teve a oportunidade de produzir a sua própria muda de plantas medicinais, tendo como base 0 reaproveitamento de materiais recicláveis, usados como recipientes, e do composto orgânico gerado a partir do resíduo orgânico.

0 ensejo de encerramento do ciclo de oficinas foi a realização de um Cine Debate. Os alunos assistiram a um filme que retrata a vida em um planeta coberto de lixo, onde o robô Wall $E$ tem como objetivo limpar toda a sujeira enquanto os humanos vivem em uma nave. Após a exibição, discutiu-se o tema. Para a orientação da discussão, foram abordadas cenas específicas do filme. Assim, foram retomados os conceitos trabalhados ao longo do projeto, culminando no entendimento de que quando se trata do planeta, a expressão "jogar o lixo fora" toma outra proporção.

Ao longo do projeto foi possível observar a mudança gerada na visão dos participantes sobre o meio ambiente. Durante as conversas e as ações esses alunos demonstraram interesse em ajudar a construir um mundo melhor. 0 sentimento de cuidado e de responsabilidade foi gerado, a primeira semente para 0 desenvolvimento de um futuro mais sustentável foi plantada. Basta continuar, por meio da educação, fornecendo o suporte necessário para o desenvolvimento de indivíduos responsáveis por suas ações na relação com o meio ambiente.

\section{Referências}

BARBOSA DE MEDEIROS, Aurélia et al. A Importância da educação ambiental nas escolas nas séries iniciais. Revista Faculdade Montes Belos, v. 4, n. 1, 2011.

BRASIL. Lei $\mathbf{n}^{\circ} \mathbf{9 . 7 9 5}$, de 27 de abril de 1999. Dispõe sobre a educação ambiental, institui a Política Nacional de Educação Ambiental e dá outras providências. Disponível em: http:// www.planalto.gov.br/ccivil_03/LEIS/I9795.htm. Acesso em: 03 mar. 2018.

Diretrizes Curriculares Nacionais para a Educação Ambiental. In: BRASIL.

Diretrizes Curriculares Nacionais para a Educação Básica: diversidade e inclusão. Brasília: Conselho Nacional de Educação: Ministério da Educação, Secretaria de Educação Continuada, Alfabetização, Diversidade e Inclusão, 2013. 480 p.

CONAMA. Resolução nº 275, de 25 de abril de 2001. Publicada no DOU no 117-E, de 19 de junho de 2001, Seção 1, p. 80. Disponível em: http://www.mma.gov.br/port/conama/res/ res01/res27501.html. Acesso em: 03 mar. 2018. 